\title{
The ethnic question in an environment of insecurity: the Kurds in Turkey
}

\section{Ahmet Icduygu , David Romano \& Ibrahim Sirkeci}

To cite this article: Ahmet Icduygu , David Romano \& Ibrahim Sirkeci (1999) The ethnic question in an environment of insecurity: the Kurds in Turkey, Ethnic and Racial Studies, 22:6, 991-1010, DOI: $10.1080 / 014198799329215$

To link to this article: http://dx.doi.org/10.1080/014198799329215

曲 Published online: 07 Dec 2010.

Submit your article to this journal $\pi$

Џll Article views: 1152

Q View related articles ¿

4 Citing articles: 48 View citing articles 4 


\title{
The ethnic question in an environment of insecurity: the Kurds in Turkey
}

\author{
Ahmet İçduygu, David Romano and İbrahim Sirkeci
}

\begin{abstract}
This article examines the effect that a poor structural context, what we term an "environment of insecurity", has on the Kurdish ethnic nationalist mobilization in Turkey. The empirical evidence for this analysis is based on data from the 1993 Turkish Demographic and Health Survey [TDHS]. The data provide, to the best of our knowledge, the first reliable and representative figures on the situation of Kurds in Turkey. Our key claim is that the Kurdish population in Turkey is relatively much worse off than the Turkish population in the country. This claim is strongly supported by the data. Many other factors also account for the ethnic nationalist mobilization, but we argue that the Turkish Kurds' environment of insecurity, materially and nonmaterially, stands out as a key package of both causal and intermediate variables behind the ethnic revival.
\end{abstract}

Keywords: Environment of insecurity; Kurds; Turkey; ethnic revival; Kurdish population; Turkish population.

\section{Introduction}

Ethnic revival is not a pressing issue everywhere. It is a dynamic phenomenon which becomes more salient in some social and economic situations though not in others (Hutchinson and Smith 1996, p. 12). One often hears that patterned social inequality, which is the source of much conflict, tension and discrimination within a society, is interrelated with heightened ethnic salience. Mainly in the countries which have not reached a certain level of economic development, any predominance of social divisions has a considerable political role, and consequen tly even otherwise benign ethnic relations may pose substantial problems of political instability. What is implied is that a poor socio-economic environment may not directly contribute to ethnic revival, but rather to greater insecurity and political instability in which ethnic markers often gain increasing 
importance. What is also implied is that ethnic revival is an outcome of quite complex interactions, including simultaneous and sequential operations of a considerable variety of interacting factors: social, economic, cultural and political. This study concerns itself with the Kurds in Turkey and how their poor structural context, what we term 'an environment of insecurity', relates to the ethnic question. In our definition of an environment of insecurity, we conceptually separate 'material insecurity' and 'non-material insecurity'. Material insecurity is measured by the relative amount and secure access to the following: income, possessions, education, health, state services and life itself. Non-material insecurity is roughly divided into the categories of language, culture (identity) and belonging (the opposite of alienation). ${ }^{1}$

Many studies on Kurds in Turkey have focused on whether or not the core of this ethnic problem is mostly 'political', involving a struggle over political rights such as administrative autonomy, language use, schooling and cultural discourse. Although it is true that at the heart of the Kurdish question lies the political dimension of the issue, this study suggests that other dimensions of this ethnic question, such as patterned socio-economic inequality, cannot be avoided altogether.

The present study emphasizes the multidimensional context of the Kurdish issue, from which the dynamics and mechanisms of the ethnic question are elaborated and possible policy initiatives are suggested. The emphasis here is on the political mobilization of ethnic identities under the pressure of socio-economic insecurity, and an attempt is made to avoid a reductionist approach.

This is a reaction against the established dominant 'orientalist' approaches to the Kurdish issue, generated mainly by Western liberals. ${ }^{2}$ These approaches generally attempt to heighten interest in the subject by narrowing the perspectives to the political dimension of the 'Kurdish ethnic problem'. Unfortunately, some tendencies that see the conflict in fairly black and white terms focus solely on its ethnic dimension. ${ }^{3}$

We also react against the ongoing dominant Turkish view, which perceives only one part of the issue, by simplistically labelling it as 'separatist terror against the integrity of the Turkish state'. It is also questionable whether the issue has only economic roots, as is widely claimed by many commentators in Turkey. ${ }^{5}$ Certainly one aspect of the issue can be labelled an 'ethnic problem', another an 'economic', and another a 'separatist terror', but we feel that these limited perspectives are reductionist in addressing the complexity of the Kurdish question. The issue now has matured; we are increasingly able to identify the multidimensional context of the subject without reducing it to merely one of its manifestations or components. ${ }^{6}$ We believe that both the variability of ethnic identity and its mobilization can be systematically addressed if the 'environment of insecurity', as a long-standing feature of the structural landscape behind the Kurdish conflict, is taken into account. 
Whatever the origins of the Kurdish question in Turkey, one fact clearly emerges: as this study will make clear, Kurds live in an environment of insecurity both materially and non-materially. Our focus here is on this environment of insecurity surrounding the Kurds in Turkey. In its simplest form, the central question we ask is: can this poor environment be seen as one of the factors determining the character of the ethnic nationalist mobilization of Kurds? Although we do not propose to prove that an environment of insecurity produces ethnic revival (many other studies $^{7}$ already concern themselves with such a question), we do attempt to show how such an environment contributes to and affects how ethnic revivals unfold. In answer, we present a very general background of the Kurdish question in Turkey and discuss what we mean by the term 'environment of insecurity', as well as how ethnic nationalist mobilization might start operating through this environment. We then prove that an environment of material and non-material insecurity does, indeed, exist for Turkey's Kurds. The data we present document the poor social context of the Kurdish people in Turkey, based on some new and interesting empirical findings.

\section{The context of the Kurdish question}

It is widely agreed that although the seeds of the Kurdish ethnic question in Turkey were derived from the early Republican period, the solidification and propagation of Kurdish ethnicity were largely products of recent years. The primary historical causes of the Kurdish issue in Turkey can be elaborated as state- and nation-building deficiencies in the early Republican period of the 1920s. Recent developments, however, appear to be more clearly driven by Kurdish ethno-nationalism, which has accelerated since 1984 in the form of guerrilla movements and limited warfare between the Kurdish Workers' Party [hereafter PKK] and Turkish government forces. Certainly, a detailing of the historical roots of the Kurdish issue in Turkey, which according to some versions stretch back centuries, is beyond the scope of this study. However, a general statement on recent developments will provide a necessary background for our discussion. ${ }^{8}$

Since its founding in 1923, the Turkish Republic has pursued aggressive assimilationist policies towards its Kurdish minority. The new republic was based solely on Turkish culture and identity, and hence did not permit the expression of Kurdish identity and language within its borders. In the 1920s and 1930s a few Kurdish revolts were harshly suppressed. These early rebellions, according to most observers, were probably more religious and tribal in nature than ethnic nationalist. ${ }^{9}$ Religious and traditional Kurds had little appetite for a secular Turkish republic, and tribal Kurdish leaders resented the new state's encroachments on their authority and power. 
However, parallel to the upswing in ethnic nationalism worldwide in the last thirty years, Kurdish nationalism in Turkey had become much more prominent by the 1970s. ${ }^{10}$ The most important Kurdish movement in Turkey's history, the PKK, has for the first time politicized and united Kurds on a much more ethnic nationalist basis than on a tribal or religious one. The movement has proved to be a thorn in the side of the Turkish government, which has been locked in a guerilla war with it since 1984 .

Recently, Turkish military and government officials have claimed victory over the PKK on the battlefield. With the military's task supposedly almost complete, officials are voicing the need to address the region's socio-economic problems, in order to make the military success an enduring one. ${ }^{11}$ Authorities have, in fact, started to present some new packages of socio-economic development for the region. ${ }^{12}$ Whether these will be carried out or prove successful to any significant degree remains to be seen. The logic behind such development efforts is to stamp out the conditions that promote discontent and allow separatist movements to thrive. On the other side of the coin, the PKK has apparently also shifted its strategy to one based less on armed confrontations, to one focusing more on political opposition activities and attempts to negotiate with Turkish officials.

Whether the PKK still espouses a separate Kurdish state is unclear. Some of the movement's statements support a federal-type solution for Kurdish demands in Turkey. ${ }^{13}$ In fact, Turkey's Kurds are faced with a plethora of options which may ameliorate their admittedly unsatisfactory conditions. Understanding these options and the context in which they exist is essential to explain present and future possibilities regarding the Kurdish question. The appeal of various possible solutions to Kurds' problems (and hence Turkey's problems as well) depends, among other things, on the identity of the Kurds in question and that identity's strength and salience.

\section{Ethnic nationalist mobilization in an environment of insecurity}

As we implied earlier, it is beyond the scope of this article to delve deeply into the nature of ethnicity and what constitutes an ethnic group. We take it as given that the Kurds are an ethnic group, although ethnic identity can vary considerably in its nature and in the way it is expressed. Ethnic definitions currently in use typically highlight a group's emphasis on common origins and descent, as well as shared characteristics based on language, race, religion, territory, culture, values and history. ${ }^{14}$ These common origins and shared characteristics may be real or fictitious. In addition, the above-named factors may be important to different degrees, or one or more may even be absent (Young 1976, p. 11).

Of particular relevance to ethnic nationalist mobilization is the distinction between a personal, private ethnic identity and a politicized 
ethnicity. By 'politicized ethnicity' we mean a situation in which ethnic identity is used as a basis from which to make claims upon the state. Through the logic of politicized ethnicity, different rights, claims to autonomy or separatism are justified by the ethnic group's difference from others within the same state. A 'private ethnic identity', on the other hand, recognizes the ethnic group's difference, but does not view this as a political issue or as a basis from which to make claims upon the state. Naturally, private ethnic identification is a necessary (albeit not sufficient) precursor to a politicized ethnicity. Also, individuals who could belong to the ethnic group but do not recognize their ethnicity in even a private sense typically exist ('dormant' or 'potential' ethnic group members). Finally, people who cannot in the foreseeable future ever belong to the ethnic group in question do exist. Usually this lack of eligibility results from identification with another or rival ethnic group, unsuitable 'racial' characteristics or appearance, differences in language, religion or culture, or similar factors. The context plays a central role when determining which eligibility factors apply.

Identity is a dynamic variable, and individuals or groups can attach varying levels of importance to their ethnic identity at different times (Young 1976; Esman 1994). As will become clear from the TurkishKurdish example that follows, a common scenario unfolds: politicized ethnic groups attempt to politicize the identity of all possible ethnic group members and then mobilize them, while governments try to convince minority ethnic groups to leave their ethnic identity in the private and personal realm. We shall now examine the choices open to Turkey's Kurds in the light of an environment of insecurity.

\section{Strategic options for Kurds in Turkey}

Four broad strategic options exist for Turkish Kurds. First, they can resign themselves to the status quo and continue to live as they have before, caught between a state which seeks to suppress their ethnic identity and ethnic nationalist movements which seek to politicize it. Secondly, they can immigrate to the west of Turkey or to another country. Thirdly, they can choose to collaborate with the Turkish state, particularly by joining the village guards. ${ }^{15}$ Finally, Kurds can decide to oppose the state, either by joining opposition groups such as the PKK or by some other means. These options are not all mutually exclusive; some can even be pursued concurrently with others. For instance, a Kurd may immigrate to the west and still oppose the state from his or her new home in Istanbul or Germany. To further illustrate the above argument, one may consider a recent Reuters article on the issue, where it is argued that,

A mixture of economic hardship and separatist conflict in southeast Turkey swells the waves of Kurdish migrants currently lapping 
Europe's shores.... Turkey says they are economic migrants.... Human rights groups say harsh tactics against Kurdish separatists drive civilians abroad.... Employment [in the southeast] is scarce and average annual household incomes are around $\$ 3,500$, compared with more than $\$ 11,000$ in Istanbul (Turkish Daily News 1998).

In the same article, a southeastern doctors' union chairman argues that '... the problem can't simply be solved economically; overall development is necessary', and cites the need for more tolerance, democracy and freedom of expression.

Kurds in Turkey must also decide whether or not they accept Turkish identity in its ethnic sense, civic sense, or not at all. ${ }^{16}$ How one identifies oneself then has important implications for both one's perceived level of insecurity and preferred strategic options. The following section examines the causal linkages between these options and the environment of insecurity, focusing on the possible outcomes and reasons for the various choices that a Turkish Kurd may make.

\section{Coping with material insecurity}

As we stated earlier, an environment of insecurity has both material and non-material (psychological) dimensions. Material needs are the easiest to measure and examine from a rational-actor perspective. ${ }^{17}$ Materially, Kurds in the southeast of Turkey may have insecure access to land, income, education, health, possessions, state resources ${ }^{18}$ and even life. The empirical data presented later in this article highlight the imbalance in the distribution of such material resources between Turkish and Kurdish-speaking populations in Turkey. Kurds may respond to such a situation in a variety of ways. First, they might opt to remain within such a status quo in the hope that the environment around them will improve, or for fear that other options will not improve or will even worsen their situation.

Secondly, they may opt to escape the conflict zone in the southeast (particularly those provinces under emergency rule) and immigrate elsewhere. In the west of Turkey Kurds are more likely to find job opportunities and less threatening harassment from state security forces or insurgents, although this is by no means guaranteed. Another option, albeit more difficult to achieve, is immigration to somewhere outside of Turkey. ${ }^{19}$ This often promises the greatest degree of security, in terms of access to jobs, physical security and freedom. Given the opportunity, most Kurds wanting to escape a situation of material insecurity would probably choose this option.

The third possibility for dealing with material insecurity involves collaborating with security forces against Kurdish ethnic challengers to the Turkish state. It must be noted here, however, that most Kurdish villages 
and tribes seem to make a collective choice of whether or not to collaborate with or oppose the state. This is generally done in order to oppose rival Kurdish groups - if a rival opposes the state, then the tribe or group in question will typically support the state in order to weaken its opponent (McDowall 1996). None the less, the scale between staying neutral or supporting the state against a rival may be tipped in favour of the state as a result of material inducements from the state. These come in the form of safety vis-à-vis state security forces, recognition and title for the group leaders, and material support such as the salaries given to village guards. ${ }^{20}$ Urban Kurds are more likely to make this choice on an individual level because of weaker tribal or kin-group bonds. The price of collaboration, of course, is the risk of attack by insurgent groups.

This leads us to the fourth option, that of opposing the state. Opposing the state does not generally improve one's material security, of course. In some cases, however, Kurds who 'have nothing to lose' and who are not given the chance to collaborate with the state may join opposition groups for material reasons. An unemployed individual or group already suspected of disloyalty by the state may join the PKK for the modest material support the organization can offer, as a way out of an otherwise intolerable situation. ${ }^{21}$ A more likely explanation for opposing the state, however, involves ideology, ethnic identity and psychological motivations. This takes us to the next aspect of an environment of insecurity - non-material insecurity.

\section{Coping with non-material insecurity}

Non-material insecurity, is, of course, related to material insecurity but not limited to material concerns. We separate material and non-material variables so that we can better analyse people's motivations and value preferences. Although it is far easier to 'objectively' measure and discuss material issues or values, this does not mean that we can ignore psychological issues. In fact, for some individuals or groups non-material motivations may play a much greater causal role than material questions. This is particularly the case when ethnic identity becomes aroused and politicized. ${ }^{22}$ We divide non-material needs into the rough categories of language, culture and belonging.

A Kurd living in Turkey may face several kinds of non-material insecurities. First of all, the Kurdish language in Turkey is suppressed and was, in fact, banned until 1991. For those whose mother tongue is Kurdish, this probably causes considerable feelings of insecurity and alienation towards the state in which they are citizens. ${ }^{23}$ If they also lack proficiency in Turkish, their alienation and disadvantages within Turkey are compounded. If culture and a secure identity are regarded as basic psychological needs, then Kurds whose mother tongue is Kurdish may experience a deep sense of non-material insecurity in Turkey. The data 


\section{8}

Ahmet Içduygu, David Romano and İbrahim Sirkeci

presented in this essay give us an approximate notion of how many people speak Kurdish as their mother tongue. Additionally, the unstable situation in the southeast, material insecurities and in some cases harassment by the state all contribute to non-material insecurity.

As regards the strategic options that a Kurd may choose from in the light of such a situation, this depends on what identity he or she has in the first place. We cannot discuss the psychological values and motivations for various options without first discussing different possible identities, since these in turn determine what an individual regards as important. As we mentioned earlier, ethnicity is one of several possible identifications and sources of motivation, including occupation, ideology, class, region and religion (Esman 1994, p. 15). In Turkey, economic disparities can cause people to develop a heightened awareness of their class or regional identity. But because the southeast of Turkey is both the poorest region and the only predominantly Kurdish part of the country, economic disparities lend themselves particularly well to heightened, politicized ethnic identity formation. Poverty in the southeast comes to be blamed on central government's neglect of or discrimination towards the Kurdish minority. Although identity is flexible and may change within certain limits, ethnicity once politicized becomes a strong motivating force that often dominates other expressions of identity (idem). Kurds who live in southeast Turkey and whose mother tongue is Kurdish are likely to experience many of the above-named insecurities, which in turn can lead them to develop a politicized ethnic identity.

This brings us back to the possible identities ${ }^{24}$ for a Kurd in Turkey and hence the options available to deal with an environment of insecurity. A person of Kurdish origin can accept Turkish identity fully (adopting the Turkish language and culture completely and above all others), at which point he or she no longer considers himself or herself a Kurd. ${ }^{25}$ Or, only the Turkish civic identity may be adopted, at which point the person in question considers himself or herself a Turkish citizen of Kurdish origin (private-personal Kurdish identity). In this case, Kurdish identity may or may not be used to make claims upon the state (that is, politicized). Or, finally, Turkish identity may be refused in both its full sense and in its civic sense. Then, politicized ethnicity is a foregone conclusion, since the person in question does not recognize the right of the Turkish state 'to include unwilling Kurds and their region within its confines'.

We would expect those who accept Turkish identity fully to pursue whatever strategies promise to improve on and mitigate their material insecurities. Because they do not identify themselves as Kurds, psychological insecurities in relation to language, culture and identity do not come into play. Those who accept a Turkish civic identity may likewise pursue any of the four main options (status quo, immigration, collaboration, opposition). They may see the best future for their own culture, 
language and identity in collaborating with the state - after proving their loyalty, the state may become less fearful of granting them more concessions on these issues. Or they may simply view the rebels fighting the state negatively. On the other hand, they may choose to oppose the state, in order to force it to grant more concessions to the Kurds and to cease repressive practices or material neglect of Kurdish areas. Finally, Kurds who completely reject Turkish identity would be expected either to resign themselves to the status quo, or immigrate, or oppose the state, although some opportunists might still choose to collaborate with the state.

For those Kurds with a highly politicized or strongly felt Kurdish identity, participating in actions against the state might function as an outlet to relieve non-material insecurities (due to group solidarity reinforcement resulting from such actions), in addition to striving for highly-prized values. In all cases, non-material needs and desires must be evaluated in combination with material ones. Often these two contradict each other, and then it is hard to determine which factors an individual will value more highly.

\section{Ramifications of an environment of insecurity}

The state and those who oppose it have interests which are more easily explained from the discussion above. 'Ethnic-entrepreneurs' seeking to oppose the state or separate Kurdish areas from Turkey want to politicize the identities of possible followers. An environment of insecurity probably promotes such politicization of identity, as increasing polarization of society and resentment against the state build up. In fact, secure population groups do not tend to radicalize or politicize their ethnicity. ${ }^{26}$

A strategic interest in promoting an environment of insecurity may explain many PKK actions including, for example, attacks on economic and civilian targets. Ethnic-entrepreneurs then attempt to interpret events and the environment of insecurity to their constituents in ethnic terms, blaming the situation on 'Turkish suppression and disregard of Kurds'. This can create a vicious circle in which an environment of insecurity promotes radicalization, thus engendering more insecurity as the state responds repressively, and people and money flee the area. Other options include attempting to alleviate insecurity from within the system, through legal means. Pro-Kurdish parties such as the Democracy Party [DEP] and the People's Democracy Party [HADEP] have courted the votes of Kurds, many of whom might hold a Turkish civic identity while at the same time demanding more material and non-material rights for Kurds in Turkey. If Kurdish options attempting to operate from within the Turkish political system are consistently suppressed, however, more Kurds may end by pursuing extra-system strategies.

The implications of this for state strategy are clear. Currently, the 


\section{Ahmet İçduygu, David Romano and İbrahim Sirkeci}

Turkish army is making many statements about the need for a government initiative in order to reduce material insecurity and poverty in the southeast, while many civilian government and non-government groups are also insisting on the need to improve human rights and general freedoms in Turkey. ${ }^{27}$ Due to its policy of curbing any display of politicized ethnicity and not showing what can be interpreted as weakness, the military does not appear to place much value on mitigating non-material insecurity for Kurds who identify themselves as Kurds in Turkey. Possibly, anti-Kurdish hardliners in Turkey feel that a climate of fear and denial of a 'Kurdish reality' will 'keep more people in line'. Ironically, Kurdish groups such as the PKK seem to feel that such a climate will serve to ethnically politicize more Kurds, sending them into the opposition camp.

\section{Data}

Our data on the Kurdish-speaking population in Turkey come from the 1993 Turkish Demographic and Health Survey [TDHS]: in particular, we benefited from the collected 'language' information based on a set of questions in this survey. The TDHS, which is part of the worldwide Demographic and Health surveys [DHS] programme, is based on a nationally representative sample of 8,619 households and 6,519 evermarried women - meaning the number of currently married, widowed or divorced women but excluding single women - younger than fifty years old. Two main types of questionnaires were used in the TDHS: the household questionnaire ${ }^{28}$ and the individual questionnaire. ${ }^{29}$ Detailed information is provided in the comprehensive report of the survey (MH, HIPS and DHS 1994).

In this study, for the purpose of our analysis, we make less use of the individual data than of the household data. The household data included the question on 'language used for conducting the interview'. The interviewers were asked to indicate the language from a list which included 'Turkish', 'Arabic', 'Kurdish', ${ }^{30}$ or 'other, with a specification'. The answers to this question provide the basis for our subsequent analyses. The households that preferred to have the interview conducted in Kurdish we categorize as Kurdish households, which we compare to Turkish households: the socio-economic characteristics of these households are elaborated and consequently the concept of a material environment of insecurity is operationalized mainly by contrasting the case of Kurdish households with their Turkish counterparts.

The only information used here from the individual questionnaire of the TDHS is about 'mother tongue', which was used to estimate the total Kurdish population in Turkey and its distribution throughout the country. Because the individual data set is quite rich in terms of its reference to mother tongue, it is possible for the first time in more than thirty 
years to estimate the Kurdish population in Turkey and its various characteristics, based on a representative sample. The questions asked a respondent about her mother tongue, and that of her parents, her husband, and her husband's parents. We operationalized this information as follows: if any of these questions was answered as 'Kurdish', we considered the respondent to be a 'Kurd', and consequently her household to be 'Kurdish' for the purpose of estimating the total Kurdish population. ${ }^{31}$

\section{Analytical discussion of the environment of insecurity}

When the subject matter is about an ethnic population in a given territory, its size and distribution become a focus of interest. In fact, this is also true for the Kurds in Turkey. The size of the Kurdish population in the country and its distribution have been a long-standing and controversial issue (Mutlu 1996, p. 517). The lack of straightforward and reliable information is well known, and the generally inadequate existing sources do not provide a satisfactory account of the size and distribution of the Kurdish population. Apart from the scarcity and inadequacy of basic information, as mentioned earlier there is a general difficulty in determining the ethnicity of people at both theoretical and practical levels, so that the question of who will be considered Kurdish remains disputed. We take the information on 'Kurdish language' as a measure for defining the Kurdish population.

Implying intuitive guesses (often without acknowledging any source), various contradictory estimates of the Kurdish population in Turkey are given: for instance, the estimates of the Kurdish population in the early 1990s varies from 3 million to 20 million. ${ }^{32}$ Again without any concrete evidence, some argue that the majority of the Kurds now live in the western part of the country, whereas others claim that the vast majority of Kurds are still in the eastern and southeastern regions. ${ }^{33}$ The considerable discrepancy in the figures about the Kurds is because of the lack of reliable data. ${ }^{34}$ There were only two notable studies that estimated the size and distribution of the Kurdish-speaking population in Turkey in the early 1990s. These studies extrapolated their estimates from the last available Turkish Census data (1965) containing mother-tongue questions. In Mutlu's study (1996), he gives the number of Kurds in Turkey as just over 7 million for 1990; while according to Özsoy, Koç and Toros (1992), there were 3.6 million people with Kurdish as their mother tongue in 1992, and the total figure rose to 6.2 million when those whose second language was Kurdish were counted. These two estimates account for 10.7 per cent and 12.6 per cent of Turkey's total population respectively. As far as the regional distribution of Kurds is concerned, the former study does not make any direct inference, but it implies that more than 90 per cent of the Kurds live in the traditionally Kurdish-dominated 


\section{Ahmet İçduygu, David Romano and İbrahim Sirkeci}

areas, that is, in the east and southeast parts of the country. The corresponding figure given by Mutlu is about two-thirds of the Kurdish population. ${ }^{35}$

The 1993 TDHS data used here, however, provide us with a unique opportunity in which we are able to calculate the size and distribution of the Kurdish population in Turkey, based on a nationally representative sample. Accordingly, we estimate that in 1993 Kurds (Kurdish speakers) account for 15 per cent of the total population in Turkey. ${ }^{36}$ In other words, the size of the Kurdish population is around 8.9 million out of a total of 59.9 million people living in the country. ${ }^{37}$ As stated earlier, the Kurds of Turkey were historically the inhabitants of the eastern and southeastern regions of the country. Although they have dispersed over other areas of Turkey through migrations of different kinds, voluntary and involuntary, it is still the case that the majority of Kurds live in these areas where they are rooted. Our analysis of the TDHS data indicates that 70 per cent of the Kurdish population in Turkey is located in the east of the country, including the southeast. This implies that contrary to the well-established view of recent years that more than half of Turkey's Kurds live in the western parts of Turkey, the traditional Kurdish areas are still the home of the majority of the Kurdish people. In fact, our findings correspond to those in Mutlu's recent study (1996, p. 533), which estimated that over 65 per cent of Turkey's Kurds reside in the eastern and southeastern regions. ${ }^{38}$ It is widely recognized that these two regions, which cover Turkey's largest and most mountainous areas, are the least densely settled, the least industrialized and, socio-economically, the least developed areas of the country.

Various social and economic indicators show that these two regions form an environment of insecurity for their inhabitants. A comparison between the western region ${ }^{39}$ of the country, which is the most developed part, and the eastern region including the southeast, for instance, reflects that in the mid-1990s there was significant socio-economic inequality between the regions. The western region's per-capita gross national product was US $\$ 2,000$, the eastern region's was US\$ 700; the western region's total fertility rate was 2 , the eastern region's was over 4 ; the western infant mortality rate was 43 , the eastern region's was 60 ; the western region's illiteracy rate was 14 , the eastern region's was 26 ; the western region's number of health personnel per 1,000 people was 3.2, the eastern region's was $2 .^{40}$

Thus, it is not difficult to make a list of sharp statistical differences showing a striking contrast between these regions. They are even more strikingly different in their wider social, political, cultural and physical environments: in the eastern region, there is the long-established presence of a more than two-decade old state of emergency; an estimated 35,000 people have been rounded up and killed in the region since the early 1980s; in 3,000 villages of the region, schools have been closed 
down, leaving 1.5 million children without education; over 3,000 villages have been evacuated; more than an estimated 3 million people have left the region in the last twenty years; ${ }^{41}$ and every year the traditionally long and cold winter makes transportation, communication and every kind of mobility extremely difficult within-region and between regions. For the people living there it is not easy to be involved in, or compelled to live in, the dynamic interplay of such conditions. Coping with the difficult nature of this environment of insecurity is a most challenging task.

As a crucial element of non-material insecurity, the status of Kurdish language in Turkey must be taken into consideration. We noted earlier that of the 60 million people living in Turkey, some 9 million are Kurds, whose mother tongue is not officially recognized; its use is even socially discouraged. There has been a long-standing political and cultural repression of the Kurdish language in Turkey, which in itself creates an environment of non-material insecurity: no schooling in Kurdish is in operation and Kurdish radio and television programmes are not allowed. Additionally, speaking Kurdish in public was a legal offence for some time, and the ban on Kurdish has been strictly implemented during different periods. For example, giving Kurdish names to children was effectively forbidden, and the Kurdish names of several geographical locations have been changed. Given the psychological and sociological importance of an individual's mother tongue, the suppression of the Kurdish language in Turkey no doubt greatly exacerbates Kurds' feelings of non-material insecurity.

The data on education, in addition to the fact that no Kurdish schools exist, are revealing: although primary education is compulsory in Turkey, as the TDHS data reveal only 61 per cent of Kurdish men and 38 per cent of Kurdish women have completed primary school; on a regional basis, what is also striking is that among those living in the eastern regions, two Kurdish men in every five, and two Kurdish women in every three, have received no schooling at all. Many Kurdish men only learn Turkish when they are drafted into military service.

Lack of education and proficiency in Turkish severely limits Kurds' socio-economic opportunities, and probably engenders feelings of psychological insecurity and alienation. As we mentioned during our discussion of ethnic nationalist mobilization, dissident movements such as the PKK are much more attractive to people who have little in the way of other options to alter their lot in life. Even without considering the economic deprivation in the region, the psychological insecurity caused by the emergency rule, human rights violations, PKK and government fighting, killings and disappearances of civilians, village evacuations, and general outgoing migrations no doubt creates a highly unsatisfactory status quo for Kurds in the east.

On the material side of the issue, overcrowding and lack of acceptable living conditions are pervasive in the east. 'Unacceptable' living 


\section{Ahmet İçduygu, David Romano and İbrahim Sirkeci}

conditions and lack of opportunity are relative, and in this sense material insecurity resembles Gurr's (1970) 'relative deprivation'. Our concept encompasses more than relative deprivation, however (as the discussion on non-material insecurity should make clear). The TDHS data indicate that only 4 per cent of the households in Turkey consist of one person, and 55 per cent contain no more than five persons. Among the 8,619 households interviewed, only 10 per cent have eight or more people. The proportion of households with more members is overwhelmingly higher in Kurdish households: among the identified 289 Kurdish households, less than 2 per cent consist of only one person; 70 per cent contain six or more people, and one-third of the households have nine or more people. For the Kurdish households, the average size is more than seven people, whereas it is less than five people for the Turkish households.

Less than half (48 per cent) of the Kurdish households are in rural areas, and the composition of those households is different from that of those in urban areas. For instance, the proportion of households with nine or more people is 26 per cent in urban areas, whereas it is 41 per cent in rural areas. The corresponding figures for the Turkish households are 3 and 11 per cent respectively. Two main reasons for the larger Kurdish household size are the greater number of children and the tradition of extended families. Arguing that the household composition often determines the allocation of resources (both material and nonmaterial) available to household members, and considering that the size of the household affects the well-being of its members, one can easily claim that when the size of the household is large, overcrowding can lead to 'an environment of insecurity'.

In order to evaluate the more immediate socio-economic environment of the Kurdish-speaking people in Turkey, we looked at some specific information about their household conditions. Within this context, we dealt with the following four questions: What is the source of drinking water in the households? What are the toilet facilities of the house? What is the main material of the floor in the house? How many people per sleeping room are there in the house?

While overall 63 per cent of the households in Turkey get drinking water from pipes, this proportion is 64 per cent for the Turkish-speaking households and 42 per cent for the Kurdish-speaking ones. In the Kurdish households, water from springs is the second main source of drinking water ( 20 per cent), and another 13 per cent obtain water from a public well. The second source of drinking water in Turkish households also comes from springs ( 13 per cent), but the third source is bottled water ( 9 per cent). In the Kurdish households the use of bottled water is less than one per cent.

Modern sanitation facilities are not widely available in the Kurdish households, pit toilets are used instead (47 per cent), and more than onefifth of the Kurdish households have no toilet facilities at all. Among the 
Turkish households, a large proportion (60 per cent) use flush toilets. Cement, a generally poor-quality flooring material, is the most common for dwelling units in Turkey (34 per cent): more than two-thirds of the Kurdish households have such flooring whereas only one third of the Turkish households have. More traditional and poor flooring material are used in the Kurdish dwelling units compared with more modern and affluent materials used in the Turkish households: the flooring material of one in five Kurdish households is earth, while that of one in four Turkish households is either polished wood or marley.

The more striking difference between the Kurdish and Turkish households concerns their level of crowding, measured by the number of people per sleeping room. As a summary indicator, the mean number of people per sleeping room is 2.6 for the Turkish households but 4.6 for the Kurdish households. The sleeping room is shared by one or two people in about 53 per cent of Turkish households, but this proportion drops to 14 per cent of Kurdish households. The proportion of five or more people sharing one sleeping room is 45 per cent in Kurdish households, whereas it is only 8 per cent in Turkish households.

As another set of indicators of household socio-economic status, the availability of durable consumer goods is taken into account. The existence or non-existence of particular goods at home has some specific implications in terms of an environment of insecurity: for instance, not having a radio, or television, or telephone, limits the access of household members to the outside world; having a refrigerator prolongs the freshness of food; having more books exposes household members to new ideas; and having a car allows greater access to many services outside the local area. Electrical appliances such as refrigerators, televisions, or radio cassette players, are the most common household durable goods in Turkey: 88 per cent of the Turkish households and 71 per cent of the Kurdish households own a refrigerator, and 88 per cent of Turkish households and 61 per cent of Kurdish households have a radio cassette player. Around three in five Turkish households have a telephone whereas less than a quarter of the Kurdish households enjoy this utility. More than half of the Turkish households have a vacuum cleaner; less than one-tenth of the Kurdish households have one. Car ownership is almost four times more common among the Turkish housholds than among the Kurdish ones.

Taking these household goods and facilities into consideration one can easily show that a considerable number of Kurdish households have a low level of socio-economic status compared with their Turkish counterparts. In the TDHS, sampled households were also asked if they had more than thirty books: almost a quarter of the Turkish households have a library containing more than thirty books whereas only one per cent of the Kurdish households have a comparable number. This information is important, since it shows that Kurdish households are less likely to have the same educational opportunities as Turkish households. 


\section{Conclusion}

Having briefly discussed the history of the Kurdish issue in Turkey, this article presented a theoretical tool to help us better understand Kurdish ethnic revival and mobilization: the environment of insecurity. We divided this concept into both material insecurity and non-material insecurity. We then used the insecurity concept to illuminate the strategic options and key issues of ethnic nationalist mobilization in Turkey. Following this, the data we presented explain how and why an environment of insecurity holds sway for Turkish Kurds. The data contained here are of particular importance, since to the best of our knowledge this is the first time such relevant and representative statistics on the Kurds are available. Through such data we were able to paint a more illuminating and accurate picture of the Kurds' situation in Turkey.

The considerations advanced in this study lead to the following conclusions: although a variety of complex factors produce and affect ethnic revivals, the environment of insecurity stands out as a key package of both causal and intermediate variables. As our data show, Kurds in Turkey are materially much worse off than the rest of the Turkish population. In addition, they face significant non-material insecurities and threats. We can therefore assume that they would seek to pursue various available options (status quo, emigration, collaboration, opposition) to improve their environment of insecurity. When considering possibilities and policies that would address the situation in Turkey, we need to keep these facts in mind. Not all cases of ethnic revival involve an environment of insecurity as we use the term here. For instance, although Basque and Quebec separatists often discuss threats to their language and culture, they do not face the same degree of material and non-material insecurity as Kurds do. Nor is the distinction simply one of ethnic nationalism in industrialized countries versus that of less developed countries. We would not attempt to apply the environment of insecurity concept (as we use it in this article) to the case of Chinese or Indian minorities in South Asia and Africa respectively.

The theoretical package presented here could fit in well with studies that examine the nexus of modernization and ethnic politics. Modernization and uneven development, coupled with certain kinds of state policies, are also typical creators of an environment of insecurity in the first place. Previous studies, such as Gurr's (1970) and Hechter's (1975), have also analysed some of the factors we present. We feel, however, that the environment of insecurity concept presents a more holistic approach, albeit one that retains enough simplicity to grant us a genuinely better understanding of the subject matter in hand. But we do not have precise measures for the environment of insecurity and its contribution to ethnic revival; the argument here is heuristic and illuminative, not fully explanatory. We believe, however, that researchers can eventually operationalize the key variables and specify the effects of the environment of 
insecurity. Our article presents the first step in this direction. In time, on the basis of a more elaborate theoretical framework and available data, we may be able to show clearly the impact of a poor structural context on ethnic revival and ethnic nationalist mobilization.

\section{Notes}

1. Although these factors will be elaborated later in the article, it should be obvious that some variables (such as language) play a role in both material and non-material insecurity. The two kinds of insecurity are, of course, interrelated; our division of the two is for the sake of conceptual clarity and understanding.

2. For instance, Mango (1994, p. 976) points out these Western Liberal views on the Kurdish question in Turkey.

3. What we claimed is that a successful conflict regulation strategy, as illustrated for instance in the case of the Northern Ireland conflict by O'Duffy (1993, p. 128-50) must be based upon the multidimensional nature of the conflict, which necessitates a full elaboration of the factors that contribute to the dynamic nature of the conflict.

4. For a discussion of terrorist actions vis- $a$-vis the Kurdish issue see, for instance, Criss (1995; 2000 forthcoming)

5. As an interesting example of the cases in which the only expressed aspect of the Kurdish issue is the economic aspect, Bülent Ecevit, Prime Minister and the leader of Democratic Left Party, often calls the problem the 'Southeastern Question', and claims that 'the problem' is solely the product of an impoverished region.

6. Indeed, some of the earlier studies on the Kurdish issue also point out the complex nature of the problem. A notable example of this kind which deserves a mention here is İsmail Beșikçi's work. See for instance Beșikçi (1969; n.d.).

7. Some of the most famous of these include Gurr (1970), Enloe (1973) and Hechter (1975).

8. For a more detailed historical account of the Kurdish issue in Turkey, see Gunter (1988), Barkey (1993), Gençkaya (1996) and McDowall (1996).

9. For further discussion regarding the nature of these revolts, see van Bruinessen (1992a), and McDowall (1996).

10. See, van Bruinessen (1998, p. 39).

11. For example, in an 18 November 1997 Milliyet article by Yalçın Ḋoğan, the Turkish army General Staff is quoted as stating 'Dry up the swamp rather than fighting with the flies'. This metaphor was meant to express the need for economic and social steps in the region, in order to reduce separatist sentiments.

12. For instance, the Eastern Holding, established by the Istanbul Chamber of Commerce, announced recently that it had gathered sixty-nine partners and 2-billion dollars and would launch twenty-five agricultural development projects in the Kurdishdominated southeast region. In addition to these private enterprises, the Turkish government has also extended credit incentives to investors in the region.

13. BBC SWB (6 July 1998).

14. For a detailed discussion of the nature of ethnic identity, see Hutchinson and Smith (1996), or Young (1976).

15. In 1985 the Turkish government decided to arm villagers in order to create an additional local anti-PKK force.

16. See Kirşçi and Winrow (1997, pp. 186-208), as well as van Bruinessen (1992b, pp. 33-67), for a more detailed discussion of various identities available to Kurds in Turkey.

17. Hence their centrality for resource mobilization and rational choice theorists.

18. Lack of fluency in Turkish, especially, can cause difficulties whenever the need arises to deal with the state bureaucracy (courts, schools, municipal issues, etc.).

19. Although there is no direct reliable figure on the Kurdish emigration from Turkey to other countries it is estimated that at least 20 per cent of the total number of Turkish 


\section{Ahmet $\dot{I} c ̧ d u y g u$, David Romano and Ibrahim Sirkeci}

migrants abroad, which amounts to 3-million people in the late 1990s, are Kurdish. For a detailed discussion see Faist (1998). In any case, the proportion of Kurdish migrants abroad is probably higher than their proportion of the population in Turkey.

20. See, ch. 19 in McDowall (1996).

21. It is possible that the PKK, via funds accumulated from smuggling, drug trafficking, sympathizers, or other means, offers its supporters substantial material benefits. There is not enough reliable evidence regarding such a possibility, however, and as a result we must only keep this possibility in mind.

22. Young (1976), Esman (1994), and Horowitz (1985), all make this argument as well. 23. For a discussion on the importance of mother tongue for psychological and sociological well-being, see Skutnabb-Kangas (1990).

24. In a survey (TOBB Report 1995) conducted in three predominantly Kurdish provinces of the southeast (Diyarbakır, Batman, and Mardin) and in three provinces in the south which receive intense Kurdish migration (Adana, Mersin, and Antalya), it was found that 40 per cent of the respondents refer to Kurdish ethnicity as the basis of their identity, whereas only 22 per cent self-identify as Turkish. In another earlier survey conducted in the Kurdish-dominated southeast region, 22 per cent of those surveyed considered themselves Turkish. However, when respondents who reacted to a Turkish identity question by not giving any response (30 per cent) are added to those who identify themselves as 'human beings' ( 35 per cent) and as Kurds (19 per cent), it becomes clear that a large proportion (84 per cent) of Kurds do not primarily consider themselves Turkish.

25. See Kirşçi and Winrow (1996, pp. 124-5), for more details regarding this choice of identities.

26. Even in a country as materially secure as Canada, Quebec separatism only appeals to people or 'makes sense' when threats to French language and culture in Quebec are invoked as reasons for needing a separate Québécois state. See Noel (1993).

27. In an interview with the Turkish Daily News (1997), State Minister Hikmet Sami Turk discusses the need for human rights initiatives to deal with the situation.

28. The household questionnaire includes demographic and social information on all members of the household. Information is also available on household living arrangements and material circumstances, including water supply, sanitation, flooring material and ownership of consumer goods.

29. The individual questionnaire, which was applied to the sampled ever-married women, provides detailed information on levels and trends of fertility, infant and child mortality, family planning, and maternal and child health.

30. We refer to all the various dialects such as Kurmanc, Zaza, Sorani and Gorani as 'Kurdish'. The major Kurdish dialects used in Turkey are Kurmanc and Zaza. Based on the categories used in TDHS, in our study the term 'Kurdish' refers to all those who speak Kurmanc and Zaza.

31. As argued by Mutlu (1996, p. 518) the principal emic marker of Kurdishness has been language. One must bear in mind that especially due to the assimilationist policies pursued in Turkey, many people may no longer speak Kurdish yet still consider themselves Kurds. Others are often reluctant to refer to their Kurdish origins or admit to knowing Kurdish. For these reasons, our estimates of the number of Kurds may be conservative. On the other hand, the above two possibilities may be counterbalanced by those situations in which someone in the family speaks Kurdish, yet the family does not consider itself primarily Kurdish. Nevertheless, the best available tool for counting the number of Kurds remains mother-tongue data.

32. For various estimates of the number of Kurds, see for instance Mutlu (1996, p. 534).

33. Five (Western, Southern, Central, Northern and Eastern) or seven (Marmara, Aegean, Mediterranean, Central, Black Sea, Eastern, and Southeastern) regions are distinguished in Turkey, reflecting to some extent differences in socio-economic development levels and demographic conditions among the sections of the country. In our study, based 
on the TDHS sampling framework, the five-region breakdown is used, in which the Eastern region includes the Southeastern region. The Eastern region includes the following provinces: Adıyaman, Ağrı, Ardahan, Batman, Bayburt, Bingöl, Bitlis, Diyarbakır, Elazı̆ğ, Erzincan, Erzurum, Gümüșhane, Hakkari, Iğdır, Kars, Malatya, K.Maraș, Mardin, Muș, Siirt, Sivas, Șirnak, Ș.Urfa, Tunceli, Van.

34. In fact, the only data source which might provide some estimates is the Turkish Population Census, carried out first in 1927 and then quinquennially after 1935. The relevant questions asked in the census are about the respondent's mother tongue, as well as the next best spoken language. Language data from the censuses were published until 1965; but for political reasons, after 1970 the data were not published, even though the questions were included in the questionnaire. Finally, the questions were dropped from the questionnaire of the 1990 census.

35. It is possible, however, that Kurds in the west of Turkey no longer speak Kurdish or will not admit to speaking it, because of the social pressure of their new non-Kurdish milieu.

36. If we take the proportion of households in which the interview is conducted in Kurdish, the size of the Kurdish population would be around 6 per cent, which is well below the assumed proportional ranges cited by many studies. This implies that Kurdish identity, which may be reflected by the spoken Kurdish language, has been abandoned voluntarily or involuntarily by many Kurds in Turkey.

37. An account of the size, distribution and some other demographic characteristics of the Kurdish population will be presented in fuller detail by Sirkeci and İçduygu (1998).

38. The Southeastern region covers Adiyaman, Batman, Diyarbakır, Hakkari, Mardin, Siirt, Sivas, Ș.Urfa, Șirnak. The Eastern region comprises Ağrı, Ardahan, Bayburt, Bingöl, Bitlis, Elazı̆ğ, Erzincan, Erzurum, Gümüșhane, Iğdır, Kars, Malatya, K.Maraș Muș Sivas, Tunceli, Van.

39. The Western region is composed of Aydın, Balıkesir, Bursa, Çanakkale, Denizli, Edirne, İstanbul, İzmir, Kırklareli, Kocaeli, Manisa, Sakarya, Tekirdăg.

40. These figures are estimated by the authors based on the data obtained from the State Institute of Statistics.

41. Various disturbing statistics on the situation in the Southeast are often given by different sources. See, for instance, Criss $(1995 ; 2000)$ and Beriker-Atiyas (1997).

\section{References}

BARKEY, H.J. 1993 'Turkey's Kurdish dilemma', Survival, vol. 35, no. 4

BBC SWB (British Broadcasting Corporation, Summary of World Broadcasting), 1998, 'Kurdish Party says yes to appeals for dialogue', London, 6 July

BEȘIKÇİ, İ. 1969 Doğu Anadolu'nun Düzeni (The Order of the Eastern Anatoia), Ankara: E Yayınları.

—_ n.d. Bilim-Resmi İdeology, Devlet-Demokrasi ve Kürt Sorunu (Science-Official Ideology, State-Democracy and Kurdish Question), İstanbul: Alan Yayınc1lık.

BERIKER-ATIYAS, N. 1997 'The Kurdish conflict in Turkey: issues, parties and prospects', Security Dialogue, vol. 28, no. 4

CRISS, N.B. 1995 'The nature of PKK terrorism in Turkey', Studies in Conflict and Terrorism, vol. 13

- 2000 (forthcoming) 'Terrorism against Turkey: the issue of international cooperation', The Journal of Conflict Studies

DOĞAN, Y. 1997 article in Milliyet (18 November)

ENLOE, C. 1973 Ethnic Conflict and Political Development, Boston, MA: Little Brown

ESMAN, M. 1994 Ethnic Politics, Ithaca: Cornell University Press

FAIST, T. 1998 'International Migration and Transnational Social Spaces', InIIS-Arbeitspa-

pier Nr. 9/98, Bremen: Universität Bremen 


\section{Ahmet İçduygu, David Romano and İbrahim Sirkeci}

GENÇKAYA, O.F. 1996 'The Kurdish issue in Turkish politics: an overview', Islamic World Report, vol.1, no.3

GUNTER, M.M. 1988 'The Kurdish problem in Turkey', Middle East Journal, vol. 42, no. 3 GURR, T.R. 1970 Why Men Rebel, (published for the Center of International Studies, Princeton University), Princeton, N.J.: Princeton University Press

HECHTER, M. 1975 Internal Colonialism: The Celtic Fringe in British National Development, 1536-1966, London: Routledge and Kegan Paul

HUTCHINSON, J. and SMITH, A.D. (eds) 1996 Ethnicity, Oxford, New York: Oxford University Press

HOROWITZ, D. 1985 Ethnic Groups in Conflict, Berkeley, CA: University of California Press KİRISÇİ, K. and WINROW, G.W. 1997 Kürt Sorunu: Kökeni ve Gelișimi (The Kurdish Question and Turkey: An Example of a Trans-state Ethnic Conflict), İstanbul: Tarih Vakf1 Yurt Yayınları.

MANGO, A. 1994 'Turks and Kurds', Middle Eastern Studies, vol.30, no.4.

McDOWALL, D. 1996 A Modern History of the Kurds, London and New York: I.B. Tauris MH, HIPS and DHS (Ministry of Health, Hacettepe Institute of Population Studies, and Macro International Inc.) 1994 Turkey, Demographic and Health Survey-1993, Ankara

MUTLU, S. 1996 'Ethnic Kurds in Turkey: a demographic study', International Journal of Middle East Studies, vol. 28

NOEL, S.J.R. 1993 'Canadian response to ethnic conflict', in J. McGARRY and B. O'LEARY (eds) The Politics of Ethnic Conflict Regulation, London: Routledge, pp. 41-61

O'DUFFY, B. 1993 'Containment or regulation,' in J. McGARRY and B. O'LEARY (eds), The Politics of Ethnic Conflict Regulation, London: Routledge, pp. 128-150

ÖZSOY, A.E., KOÇ, I. and TOROS, A. 1992 'Türkiye'nin Etnik Yapısının Anadil Sorularına Göre Analizi (Ethnic structure in Turkey as implied by the analysis of mothertongue data)', The Turkish Journal of Population Studies, vol. 14

SIRKECI, İ. and İÇDUYGU, A. 1998 'Exploring the Demography of the Kurds in Turkey: the First Evidence', Cepos Working Papers, no. 1998/3

SKUTNABB-KANGAS, T. 1990 Language, Literacy and Minorities, London: Minority Rights Group

TOBB REPORT, 1995 Dö̆u Sorunu; Teșhisler ve Tesbitler (Eastern Question; The Diagnoses and Facts), Ankara: TOBB.

TURKISH DAILY NEWS 1997 'Interview with the State Minister Hikmet Sami Türk', Turkish Daily News, 4 December

- 12 January 1998

VAN BRUINESSEN, M. 1992a Agha, Sheikh, and State, London: Zed Books $1992 b$ 'Kurdish society, ethnicity, nationalism and refugee problem', in G. Kreyen-

broek and S. Sperl (eds), The Kurds: A Contemporary Overview, London: Routledge 1998 'Shifting national and ethnic identities', Journal of Muslim Minority Affairs, vol.

18, no. 1

YAVUZ, H. 1996 'Turkey's imagined enemies': Kurds and Islamists', The World Today, April YOUNG, C. 1976 The Politics of Cultural Pluralism, Madison, WI: University of Wisconsin Press

AHMET IÇDUYGU is Associate Professor in Political Science at Bilkent University, Ankara.

DAVID ROMANO is a PhD candidate in Political Science at the University of Toronto.

IBRAHIM SIRKECI is a PhD candidate in Geography at the University of Sheffield.

ADDRESS: Department of Political Science, Bilkent University, Ankara, Turkey. 